Bilitza, D., Xiong, C. (2021): A solar activity correction term for the IRI topside electron density model. - Advances in Space Research, 68, 5, 2124-2137.

https://doi.org/10.1016/j.asr.2020.11.012 


\title{
A solar activity correction term for the IRI topside electron density model
}

\author{
Dieter Bilitza $^{\mathrm{a}, \mathrm{b}, *}$, Chao Xiong ${ }^{\mathrm{c}}$ \\ a Department of Physics and Astronomy, George Mason University, Fairfax, VA 22030, USA \\ ${ }^{\mathrm{b}}$ Heliospheric Laboratory, NASA Goddard Space Flight Center, Greenbelt, MD 20771, USA \\ ${ }^{\mathrm{c}}$ Section 2.3, Geomagnetism, GFZ German Research Centre for Geosciences, Telegrafenberg, 14473 Potsdam, Germany
}

Received 31 May 2020; received in revised form 13 September 2020; accepted 13 November 2020

\begin{abstract}
In situ measurements by the Low Earth Orbital (LEO) satellites, such as CHAMP, GRACE, and C/NOFS satellites have shown that the International Reference Ionosphere (IRI) model has shortcomings in describing the solar activity variation of the topside electron density. In particular IRI overestimates the measured densities in the topside ionosphere during the very low solar activity reached during the last solar minimum (2008-2009). We have used Alouette and ISIS topside sounder data and CHAMP, GRACE, as well as Swarm in situ measurements to deduce a correction term for the IRI electron density topside model that more accurately describes the variation with solar activity. We have used a linear variation with the solar index PF10.7 and described the latitudinal and altitudinal variation of the regression parameters A 0 and A1 (intercept and slope). We find good agreement between the regression parameters deduced from the topside sounder and from the CHAMP and GRACE observations. Swarm results show the same latitudinal structure as the other data sets, however, a scaling factor is needed to obtain agreement of the absolute values. The new model was evaluated with Alouette and ISIS topside sounder, as well as LEO satellites in situ data showing a significant improvement over the current IRI model.
\end{abstract}

(c) 2020 COSPAR. Published by Elsevier Ltd. All rights reserved.

Keywords: IRI; Topside; Solar minimum; Alouette; ISIS; CHAMP; GRACE; Swarm

\section{Introduction}

The International Reference Ionosphere (IRI) model is the international standard for Earth's ionosphere. It was developed and is being updated by a Working Group of the Committee on Space Research (COSPAR) and the International Union of Radio Science (URSI) and is the standard recommended by the International Standardization Organization (ISO), the European Cooperation for Space Standardization (ECSS) and the International Telecommunication Union (ITU) (Bilitza, 2018). As

\footnotetext{
* Corresponding author.

E-mail addresses: dbilitza@gmu.edu, dieter.bilitza-1@nasa.gov (D. Bilitza), bear@gfz-potsdam.de (C. Xiong).
}

requested by COSPAR and URSI, IRI is an empirical model that was developed based on many data sources from both ground and space observations. The IRI is improved as newer data become available and better modelling techniques are being applied and different versions of the IRI model have been released over the years. The latest version is IRI-2016 (Bilitza et al. 2017). IRI performance has been assessed in many comparisons with new data sources and in community wide model assessment studies (Shim et al. 2011, 2012, 2017, 2018).

Parameters provided by IRI include the electron density, ion composition, electron temperature, and ion temperature in the altitude range from $50 \mathrm{~km}$ to $2000 \mathrm{~km}$. Our study is focused on improving the description of electron density in the topside ionosphere. A number of studies 
had found problems with this part of the IRI model particularly during the years 2008 and 2009. Lühr and Xiong (2010) noted a significant overestimation $(50-70 \%)$ by IRI of the measurements taken during this time period by the CHAMP and GRACE satellites, at $400 \mathrm{~km}$ and $500 \mathrm{~km}$ orbital altitudes, respectively. The discrepancies occur primarily during daytime and at low/equatorial latitudes and diminish during nighttime. Klenzing et al. (2011, 2013) confirmed these results with data from the Retarding Potential Analyzer (RPA) of the Coupled Ion-Neutral Dynamics Investigation (CINDI) suite of instruments that flew on the Communication/Navigation Outage Forecast System (C/NOFS) satellite during this time period covering the altitude range 400 $850 \mathrm{~km}$. They found that the overestimation increases with altitude and that in the latitude range covered by the satellite (dip latitude $=-30^{\circ}$ to $6^{\circ}$ ) the largest discrepancies are observed near the crests of the Equatorial Ionization Anomaly (EIA). They also noted that by 2011, with increasing solar activity, the IRI predictions had returned to agreeing well with the CINDI measurements. Using data from a different instrument on C/NOFS, the Planar Langmuir Probe (PLP), Bilitza et al. (2012) found similar results.

During 2008-2009 the minimum between solar cycles 23 and 24 was reached. Compared to earlier minima this one was exceptional in that it lasted almost two years longer than its predecessors and that it reached very low levels of solar activity. IRI was developed with the existing data record, therefore it is not surprising that it did not represent conditions well that were exceptional and not covered by the prior data record. It is therefore important to use data from the minimum time period to better represent very low solar activity conditions in the IRI model for the topside electron density. This is the goal of our study as described in this paper. In addition to CHAMP, GRACE and Swarm in situ data we have also used topside sounder data from the Alouette 1,2 and ISIS 1,2 satellites.

However, we first need to take a closer look at the description of the topside electron density in IRI and investigate which specific parameters could be the cause of the observed discrepancy. Since the profile is normalized to the F2 peak density $\mathrm{NmF} 2$ and height $\mathrm{hmF} 2$, a misrepresentation of either one of these parameters could be the cause of the discrepancy. A decrease in either $\mathrm{NmF} 2$ or $\mathrm{hmF} 2$ or both would lead to decreased IRI electron density values in the topside ionosphere and therefore to a better fit with the CHAMP and GRACE data. Additionally, the topside profile shape could play an important role. A flatter profile could also produce the decrease in electron density that the measurements require. Bilitza et al. (2012) investigated the influence the very low solar activities had on $\mathrm{NmF} 2$ and $\mathrm{hmF} 2$ with the help of ionosonde data from several stations. They found that the change of these two parameters is small compared to earlier solar minima and could not produce the significant decrease in the topside electron density that would be required to get agreement with the satellite observations. Therefore, the main focus of our study will be on the IRI topside profile function and the development of a correction term that more accurately describes the variation of the topside profile with solar activity. This is in line with studies that have reported a significant contraction of the topside ionosphere during the 2008/2009 solar minimum and a lowering of the upper ion transition height (from $\mathrm{O}+$ to light ions) by $500 \mathrm{~km}$ and more (Heelis et al., 2009). Good progress has been achieved in representing these lower transition heights in IRI through changes in the ion composition model based on C/NOFS-CINDI data (Truhlik et al., 2015).

\section{Data used in this study}

The Alouette 1,2 and ISIS 1,2 topside sounder satellites have provided a wealth of information about the topside ionosphere operating over almost two solar cycles from the 1960s to the 1980s (Bilitza et al., 2003). Obtaining electron density profiles from the recorded ionograms, however, is a complex process that involved manual scaling and a mathematical inversion process. This explains why only a limited number of the topside ionograms $(\sim 10 \%)$ had been processed at the time. Table 1 lists the time periods covered by these data and the orbit parameters of the four satellites. The data sets were generated by different analysis centers and are available from NASA's Space Physics Data Facility (SPDF) at https://spdf.gsfc.nasa.gov/ pub/data/; for Alouette 1 data sets from three different analysis centers are archived at SPDF and listed in Table 1. In total there are 176,622 topside profiles of electron density covering the time period from late 1962 to late 1979 including the solar minima in $1964 / 65$ and 1976/77. It is worth noting that an ongoing data restoration effort has managed to generate more electron density profiles by using the TOPIST automated scaling and conversion software (Bilitza et al., 2004; Benson and Bilitza, 2009). These newer data are not included in the current study but will be considered in follow-on work.

As with many older data sets it is important to first screen out physically unreasonable profiles. Verhulst and Stankov (2013) had found quite a number of such cases in their analysis of the Alouette/ISIS data base. We have done this by eliminating profiles with very low F2 peak heights $(\mathrm{hmF} 2<150 \mathrm{~km})$ and profiles with very low F2 peak densities $(\ln (\mathrm{NmF} 2)<20)$. Unfortunately, in many cases the profiles do not reach all the way down to the F2 peak, because of the difficulties in scaling the topside ionogram trace in the cusp region near the peak and then inverting it into a density profile. We have obtained the peak values by fitting a Chapman layer to the lower part of the profile. Profiles are only considered if they had at least five profile points in the lower topside and if they could be fitted with a standard deviation of $3 \%$ or better. Of the 176,622 profiles in Table 1 a total of 120,058 profiles remained after this fitting and selection processes. The cleaned Alouette/ISIS data base included altogether $1,809,103$ data points covering almost two solar cycles from 1962 to 1979. To avoid biases due to coverage limits 
Table 1

Characteristics of Alouette and ISIS Orbits and Data Sets.

\begin{tabular}{|c|c|c|c|c|c|c|}
\hline Satellite & Launch Date & Height Range / km & Incl./deg. & $\begin{array}{l}\text { Time Period } \\
\text { yyddd }\end{array}$ & Number Profiles & $\begin{array}{l}\text { Vol } \\
\text { MB }\end{array}$ \\
\hline Alouette 1a & $1962-09-29$ & 1000 & 80 & $62273-63082$ & 15,706 & 6.7 \\
\hline Alouette 1a & 1962-09-29 & 1000 & 80 & $62272-66089$ & 43,614 & 12 \\
\hline Alouette 1a & $1962-09-29$ & 1000 & 80 & $62323-71350$ & 26,452 & 5.8 \\
\hline Alouette 2 & $1965-11-29$ & $500-3000$ & 80 & $65349-72192$ & 9,301 & 2.8 \\
\hline ISIS 1 & 1969-01-03 & $500-3000$ & 88 & $69033-71087$ & 38,953 & 8.2 \\
\hline \multirow[t]{2}{*}{ ISIS 2} & 1971-04-01 & 1400 & 88 & $71098-79239$ & 42,596 & 8.4 \\
\hline & & & & TOTAL: & 176,622 & \\
\hline
\end{tabular}

in space and time (Verhulst and Stankov, 2013) we have, in our modelling study, only used Alouette/ISIS averages when at least 50 data points were recorded in the specific space and time bin.

We have also used data from the more recently launched LEO missions, e.g., CHAMP, GRACE, and Swarm satellites as listed in Table 2. The electron density data of the Challenging Minisatellite Payload (CHAMP) satellite and the Swarm satellites were obtained in situ with Langmuir probes. The Gravity Recovery And Climate Experiment (GRACE) satellite consisted of two identical spacecraft orbiting closely together to obtain gravity measurements. The electron density was obtained from the K-Band Ranging (KBR) system between the two spacecraft (Xiong et al., 2010, 2015). The CHAMP and GRACE data are important for our study because they cover the 2008/9 solar minimum that reached exceptionally low solar activities and data from the Swarm satellites cover the more recent cycle $24 / 25$ minimum that again reached very low activity levels. The Swarm A and C are flying side-by-side at the same altitude with a longitudinal separation of about $1.4^{\circ}$, therefore, nearly identical in situ electron density are observed by the two satellites. This was confirmed by Xiong et al. (2016), who have statistically compared the electron density between Swarm A and C during a two-year period, and found that the ratios between their measured electron densities are about 1.013, 1.010, 1.019 for three different seasons, indicating really consistent measurements between the two satellites. Therefore, we only used the Swarm A and B data within this study.

The CHAMP and GRACE data were obtained from the Information System and Data Center (ISDC) of GFZ German Research Centre for Geosciences (https://isdc.gfzpotsdam.de/homepage/), and the Swarm data are available at the ESA's website ftp://swarm-diss.eo.esa.int/Levellb/ Latest_baselines/EFIx_LP/.

\section{Description of topside electron density in IRI-2016}

IRI-2016 (Bilitza et al., 2017) offers three options for the representation of the topside electron density profile: (a) the mathematical representation developed by Rawer et al. (1978) commonly called IRI-2001; (b) a correction of this formula based on the Alouette/ISIS topside sounder data (Bilitza, 2004), commonly called IRI-2001cor; (c) the topside profile formula developed by the NeQuick team (Radicella and Leitinger, 2001; Nava et al., 2008) denoted IRI-2007-NeQ in the rest of the paper. Comparisons with observations have found the IRI-2001cor and NeQuick options superior to the older IRI-2001 formulation that for certain conditions produces unrealistically steep, almost vertical, topside profiles. Using the Alouette/ISIS data of Table 1, Bilitza (2009) found that IRI-2001 overestimated the data with an overall average of $165 \%$, while IRI2001 cor reduced this number to $46 \%$ and IRI-2007-NeQ to $24 \%$. Based on the better overall performance the NeQuick option was adopted as the default option in IRI-2007 and later versions. It has, however, the disadvantage that it does not correctly reproduce the electron density in the Equatorial Ionization Anomaly (EIA) region at high altitudes. The well-known and well understood EIA processes generate two ionization maxima on both sides of the magnetic equator at about $15^{\circ}$ magnetic dip latitude in the $\mathrm{F}$ region and these two cusps move closer to the magnetic equator with increasing altitude until they merge in the upper topside. Bilitza (2009) showed (in his Fig. 5) that while IRI-2001cor produces the correct altitudinal picture of the EIA, the NeQuick option displays the EIA camelback signature throughout the topside ionosphere. Since all three models (and in fact most topside models) are normalized to the F-peak density, it is expected that the EIA camelback signature will propagate to higher altitudes if it is not actively counter-balanced by the mathe-

Table 2

Characteristics of the CHAMP, GRACE, and Swarm Satellites and Data Sets.

\begin{tabular}{|c|c|c|c|c|c|c|}
\hline Satellite & Launch Date & Height & Incl. & $\begin{array}{l}\text { All LTs } \\
\text { cov'd }\end{array}$ & Data Period & Number of orbits \\
\hline CHAMP & $2000-07-15$ & $330-450 \mathrm{~km}$ & 87.2 & 130 days & $8 / 2000-2 / 2010$ & 42,160 \\
\hline GRACE & $2002-03-17$ & $450-520 \mathrm{~km}$ & 89.0 & 160 days & $4 / 2002-4 / 2015$ & 56,854 \\
\hline Swarm B & $2013-11-22$ & $500-530 \mathrm{~km}$ & 88 & 141 days & $12 / 2013-12 / 2019$ & 23,206 \\
\hline
\end{tabular}


matical formalism for the topside formula. This seems to work well in the case of IRI-2001cor but not in the case of the NeQuick topside option (Bilitza, 2009). Because of this problem of the NeQuick option we decided to focus our work on an improving the IRI-2001cor topside option.

To describe the formalism of the IRI-2001cor model we have to first explain the IRI-2001 topside model. It was developed by Rawer et al. (1978) based on an analytical representation of the tabular Bent et al. (1972) model and a small amount of incoherent scatter radar data. The IRI-2001 topside electron density profile $N_{e}(h)$ is described as

$$
\begin{aligned}
& \begin{array}{l}
N_{e}(h)= \\
\begin{aligned}
Y(h)= & (1000-h m 2 \cdot \exp (-Y(h)) \\
& \quad-\delta, 394.5, \beta)+100 \cdot \zeta \cdot E(X, 300 \\
& \quad \delta, 300,100)-\zeta \cdot(X-300+\delta)]
\end{aligned} \\
X=700 \cdot(h-h m F 2) /(1000-h m F 2)+300-\delta \\
E\left(x, x_{0}, x_{s}, d\right)=\ln \left\{\left[1+\exp \left(\left(x-x_{s}\right) / d\right)\right] /\left[1+\exp \left(\left(x_{0}-x_{s}\right) / d\right)\right]\right\}
\end{array}
\end{aligned}
$$

where NmF2 and hmF2 are the F2 peak electron density and peak height and the fitting parameters $\beta, \zeta$, and $\eta$ are functions of geomagnetic latitude, F2 layer critical frequency foF2, and solar radio flux. $X$ is a modified altitude variable transforming the $F 2$ peak height to near $300 \mathrm{~km}$ with a minimized correction term $\delta$ that is a function of $\beta, \zeta$, and $\eta$. A more detailed description of the formalism is given by Bilitza (2004). A number of studies had found discrepancies between this model and measurements particularly in the upper topside where under certain conditions the formalism could produce unrealistically steep profiles. This is partly due to the fact that the underlying Bent et al. (1972) model was built with only about 40,000 Alouette 1 topside sounder profiles and so is relying on a rather limited data base. To overcome this shortcoming Bilitza (2004) introduced the correction term TCOR into Eq. (1)

$$
\begin{aligned}
N_{e}^{I R I 2001 \operatorname{cor}}(h)= & N m F 2 * \exp \{-Y(h) \\
& +\operatorname{TCOR}(h, \text { Modip }, L T)\}
\end{aligned}
$$

and determined the height-dependence of TCOR by fitting the new function (Eq. (2)) to the full set of available Alouette/ISIS data a total of 176,622 profiles (Table 1). He found that in addition to the dependence on height, variations with modified dip latitude (Modip) and local time (LT) needed to be also considered. The new formalism worked well and resulted in the significant improvement mentioned earlier. It did, however, not correct for the observed variation of the discrepancies with solar activity. While at low and very low solar activities IRI overestimated topside electron density measurements (Lühr and Xiong, 2010, Bilitza et al., 2012, Klenzing et al., 2011, 2013), several studies had reported underestimation for high solar activity conditions at low and equatorial latitudes (Abdu et al., 2008; Ogwala et al., 2019; Wan et al.,
2020). To account for these differences we introduce an additional correction term as explained in the next section.

\section{New formula for the IRI electron density profile in the topside}

In Figs. 1 and 2 we have plotted a few examples of the ratio between observational data and the predictions by IRI versus solar activity. We use the PF10.7 solar activity index that has been successfully used for modelling the topside electron density (Richards et al., 1994) and shows a good correlation with the solar Extreme Ultraviolet (EUV) radiation (Liu et al., 2006). PF10.7 is defined as the average of the daily and 81-day-mean (3 solar rotations) of the solar flux at $10.7 \mathrm{~cm}$ wavelength (F10.7)

$P F 10.7=($ F10.7_daily + F10.7_81day $) / 2$

The IRI values are determined for the same time and location as the observations. Different from the standard IRI we use the IRI-2001cor option for the topside and the Shubin (2015) option for hmF2. As explained earlier we use IRI-2001cor and not NeQuick (the IRI-2016 default) for the topside because of the more accurate representation of the EIA region in the upper topside. We have used the Shubin (2015) option and not the Altadill et al. (2013) model (the IRI-2016 default) because our comparison with Alouette and ISIS topside sounder data found the Shubin model superior to the other two hmF2 options (Mengist et al., 2020; Moses et al., 2021). This choice of IRI options is indicated in all plots by the abbreviation USC (IRI_USC on the y-axis notation) where the U stands for URSI model for foF2, S for Shubin model for hmF2 and $\mathrm{C}$ for IRI-2001cor for the topside. Following the formalism of Eq. (2) we have plotted the logarithm of the ratio. The examples in Figs. 1 and 2 show that a linear fit is a good first approximation for describing the variation with solar activity. As expected, it shows that the current IRI2001cor topside model overestimates the measurements at low and very low solar activities and underestimates the data at high solar activity. This holds true for all of our data sets from Tables 1 and 2. We also find that the variations are larger at low latitudes and high altitudes and become smaller towards middle latitudes and lower altitudes. Assuming a linear dependence, we than get

$$
\begin{aligned}
\ln \left\{N_{e}^{o b s}(h) / N_{e}^{I R I 2001 c o r}(h)\right\} & =\operatorname{SCOR}(\operatorname{PF} 10.7) \\
& =A 0+A 1 \cdot P F 10.7
\end{aligned}
$$

and with $N_{e}^{I R I n e w}(h)=N_{e}^{o b s}(h)$ we get for the corrected IRI topside formula

$$
\begin{aligned}
N_{e}^{\text {IRInew }}(h)= & N m F 2 \cdot \exp \{-Y(h) \\
& +T C O R(h, \text { Modip }, L T)+\operatorname{SCOR}(P F 10.7)\}
\end{aligned}
$$

Next we have to study how the parameters A0 and A1 change with time and location, in order to find a mathematical representation of these dependences. 

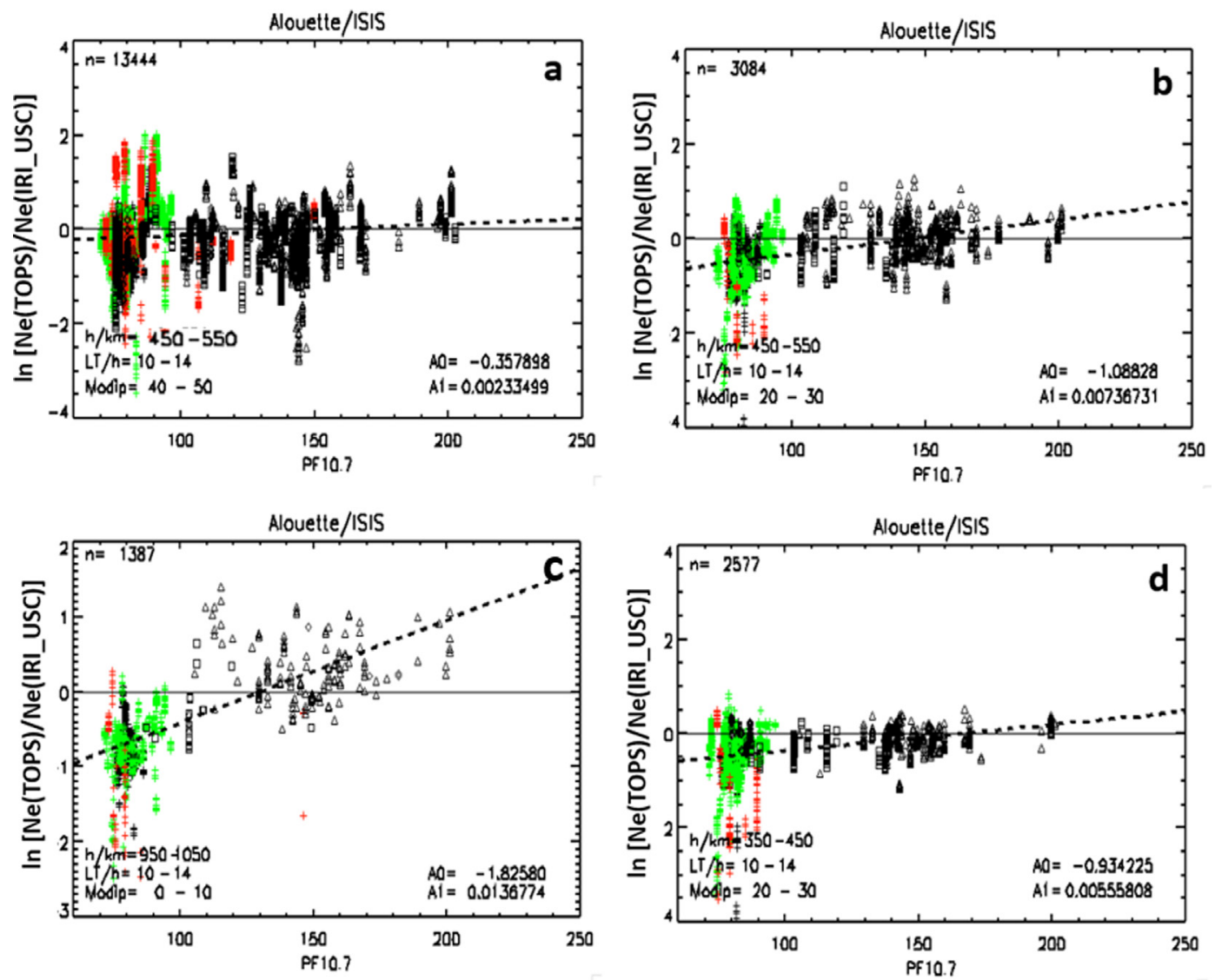

Fig. 1. a,b,c,d Logarithm of the ratio between Alouette/ISIS topside sounder data and IRI-2016 predictions vs solar activity for the height, LT, and Modip ranges specified in the lower left corner. Also shown is a linear fit (dashed line) and the fitting parameters A0 and A1 (lower right corner). The total number of points is listed in the top left corner. The data sets from Table 1 are marked with different symbols/color: Alouette 1a $(+), 1 \mathrm{~b}(+), 1 \mathrm{c}(+)$, Alouette $2(\diamond)$, ISIS-1 $(\Delta)$, ISIS-2 $(\square)$.

\section{Description of the Modip variation of the parameters A0 and A1}

In Fig. 3 we have used the Alouette/ISIS data to investigate the variation of A0 and A1 with modified dip latitude (Modip) for different altitude ranges for daytime ( $\mathrm{LT}=10-14)$ and nighttime ( $\mathrm{LT}=22-2)$ conditions. We note a significant variation with Modip during daytime while at nighttime both parameters are close to zero at low and middle Modip latitudes. During daytime the intercept parameter A0 (SCOR value at PF10.7 =0) is below zero from Modip $=-50$ to +50 producing the needed lowering of the IRI values for low solar activities. The slope parameter A1 is positive in the same Modip range indicating that the SCOR values decrease from their negative A0 values at PF10.7 $=0$ towards zero at medium solar activities and become positive for high solar activities. The lowest A0 values are reached at about the location of the EIA cusps, whereas the A1 values reach a maximum near the Modip equator. The altitude ranges with the largest values are $775-825 \mathrm{~km}$ and $975-1025 \mathrm{~km}$. All this agrees with the results of the studies by Lühr and Xiong (2010) and Klenzing et al. (2011, 2013).
Let us now look in greater detail at the Modip dependence at the altitude ranges covered by the satellites CHAMP, GRACE, and Swarm A, B. In Fig. 4a we have plotted the A0 values from Alouette/ISIS for the CHAMP altitude range centered at $400 \mathrm{~km}$ together with the CHAMP A0 values and in Fig. 4b the same for the GRACE values and Alouette/ISIS altitude range centered at $500 \mathrm{~km}$. We note the great similarity in the Modip variation of these values obtained from measurements by different satellites. They show the same distinct minima near the cusps of the EIA and a local maximum near the magnetic equator. This, however, is not the case for Swarm A0 values plotted in Fig. 4c together with the Alouette/ ISIS values for the Swarm A altitude range centered at $450 \mathrm{~km}$. The Swarm A values show the same Modip structure but need to be shifted upward by a value of 1.4 to reach the same values as we had found for Alouette/ISIS in this altitude range. Fig. $4 \mathrm{~d}$ shows that good agreement is achieved with such a shift. For Swarm B we find a similar but much smaller shift $(+0.5)$ is required to get agreement with the Alouette/ISIS data in the Swarm B altitude range centered at $530 \mathrm{~km}$. These corrections are in the same directions but a little bit larger than the adjustment ratios 

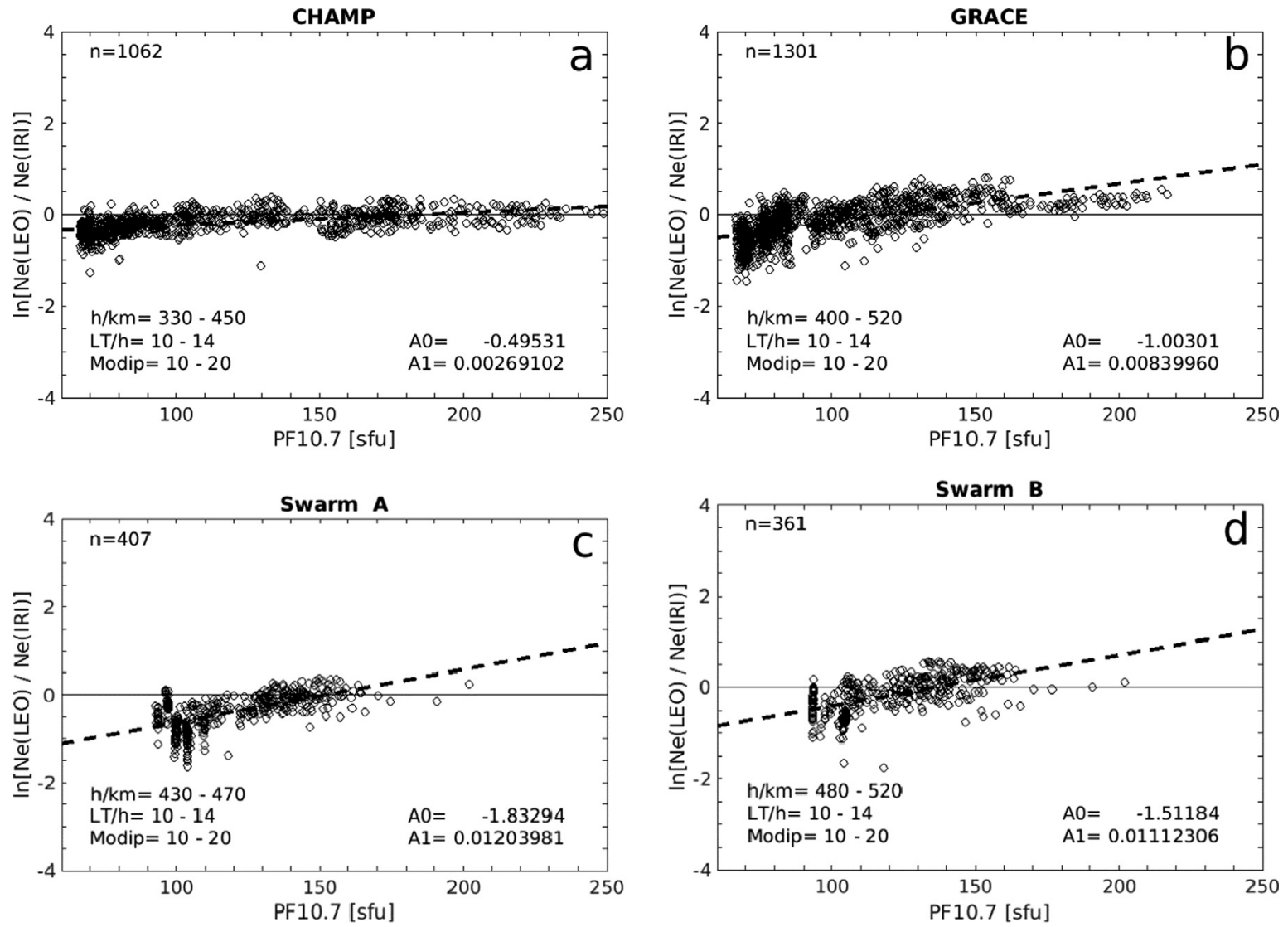

Fig. 2. a,b,c,d. Logarithm of the ratio between data from Table 2 and IRI-2016 predictions vs solar activity for the LT range, and Modip range specified in the upper right corner. Upper left panel (2a): CHAMP; upper right panel (2b): GRACE; lower left panel (2c): Swarm A; upper right panel (2d): Swarm B. Also shown is a linear fit (solid line) and the linear formula with fitting parameters A0 and A1 (upper left corner).
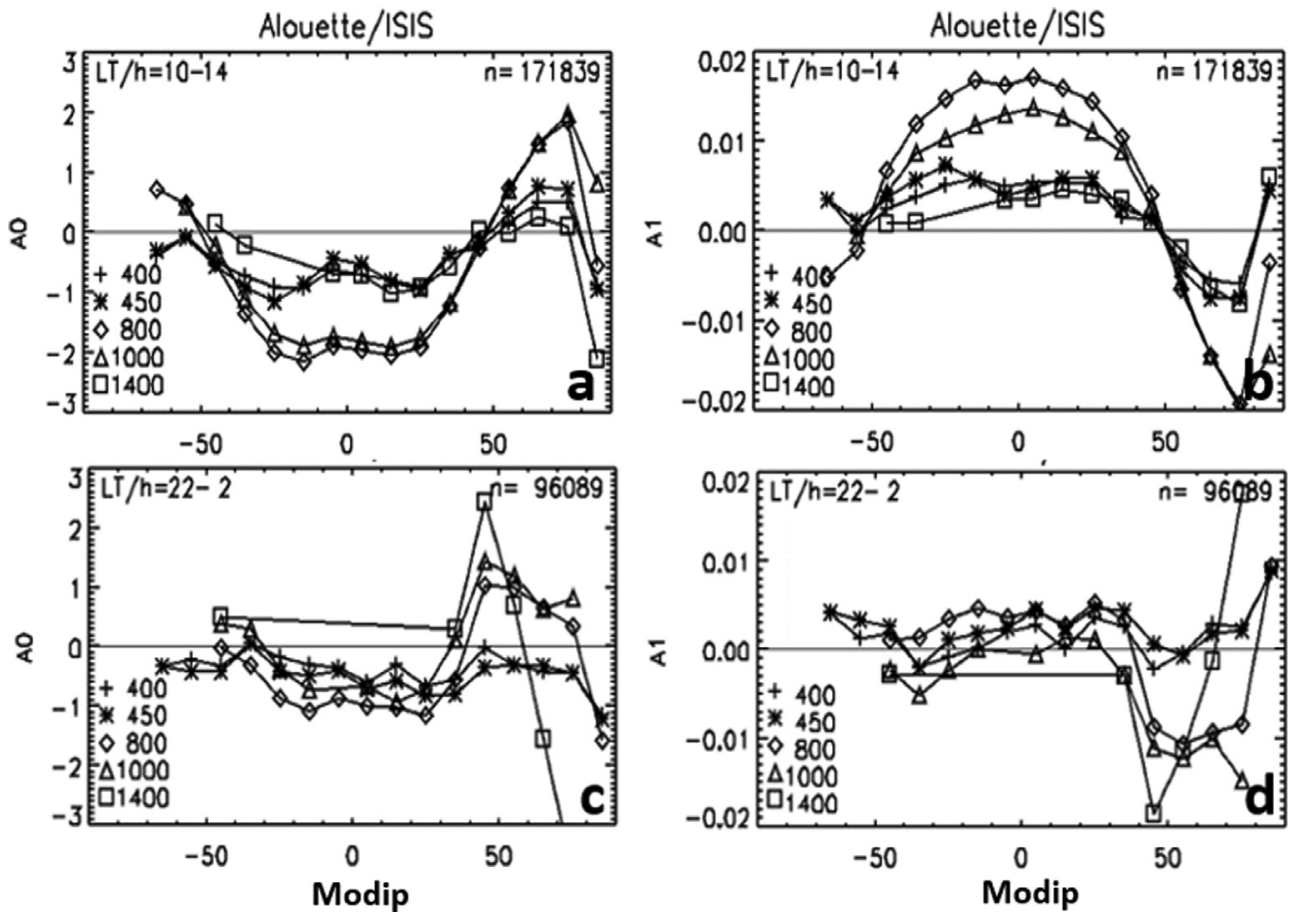

Fig. 3. a,b,c,d. Parameters A0 (left panels) and A1 (right panels) vs Modified Dip Latitude (Modip) for the Alouette/ISIS data at different altitude ranges (number in lower left $\pm 25 \mathrm{~km}$ ) for daytime ( $\mathrm{LT}=10-14$; upper panels) and night time (LT $=22-2$; lower panels). The total number of data points ( $\mathrm{n}$ ) is shown in the upper right. 

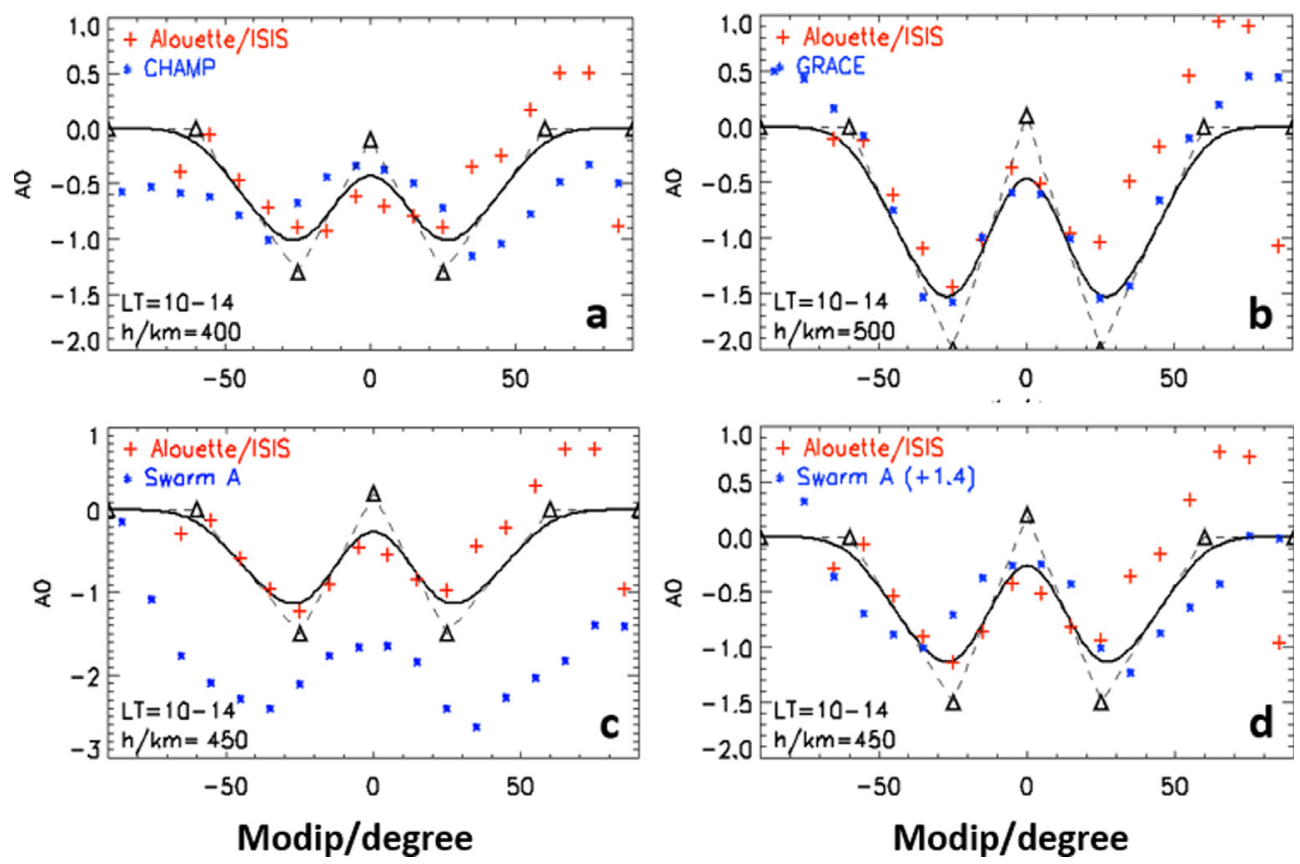

Fig. 4. a,b,c,d. The parameter A0 vs Modip during daytime (LT = 10-14) for the CHAMP data (a, upper left), the GRACE data (b, upper right), the Swarm A data (c, lower left), and the shifted Swarm A data (d, lower right) (symbol: blue *). Also shown is A0 obtained from the Alouette/ISIS data (symbol: red + ) for the corresponding altitude range noted in the lower left. The triangles $(\Delta)$ mark the fix-points used for the Booker-function approach and the solid line is the Booker function. (For interpretation of the references to color in this figure legend, the reader is referred to the web version of this article.)

reported by Lomidze et al. (2018), who had used in their validation study incoherent scatter radar and satellite radio occultation measurements. However, these values are for the intercept $\mathrm{A} 0$ and could be changed depending on necessary corrections of the slope A1.

In Fig. 5 the slope parameter A1 is shown for all four satellites from Table 2 and the corresponding values from Alouette/ISIS. Again we noted the close correlation in the Modip variation of $\mathrm{A} 1$ values from different satellites. The largest slope is found near the EIA cusps with a local minimum at the Modip equator. Taken together with the Modip variation of A0 values, it is clear that the largest solar activity corrections are required at the EIA cusps. At these locations the correction term SCOR starts out with the lowest values at very low solar activities and then shows the steepest increase towards medium and high solar activities.

Again we find that the slope values from CHAMP and GRACE agree very well with the corresponding Alouette/ISIS data. Swarm A and B, however, show the best fit with the Alouette/ISIS data when shifted by a small amount: -0.008 for Swarm A and -0.002 for Swarm B. These shifts translate into multiplicative calibration factors for electron density of 1.82/1.35 (Swarm A/B) at PF10.7 = 100 sfu, 1.49/1.285 at PF10.7 = 125 sfu (which is about the middle of the PF10.7 range covered by the Swarm data in Fig. 2), and 1.22/1.22 for PF10.7 = 150 sfu (which is about the upper limit of the PF10.7 range covered by the Swarm data in Fig. 2). This comes very close to the calibration factors that Lomidze et al. (2018) had found with incoherent scatter radar and satellite radio occultation measurements: 1.1067 for Swarm A and 1.0882 for Swarm B.

How can we represent the Modip variation pattern depicted in Figs. 3, 4, and 5? We decided to use the Booker function approach that has been successfully applied for modelling the IRI plasma temperatures. This approach divides the Modip profile into regions of constant gradient and combines these regions with Epstein transition functions. We chose the fix points Modip $=\mathrm{x}_{\mathrm{i}}=$ $-90^{\circ},-60^{\circ},-25^{\circ}, 0^{\circ},+25^{\circ},+60^{\circ},+90^{\circ}$ for $\mathrm{i}=0-6$. They are marked by triangles in Figs. 3, 4, and 5. The constant slopes in the 6 Modip ranges defined by these 7 Modip fix-points are

$\mathrm{m}_{\mathrm{i}}=\left\{\mathrm{A} 0\left(\mathrm{x}_{\mathrm{i}}\right)-\mathrm{A} 0\left(\mathrm{x}_{\mathrm{i}-1}\right)\right\} /\left(\mathrm{x}_{\mathrm{i}}-\mathrm{x}_{\mathrm{i}-1}\right) \quad \mathrm{i}=1-6$

$\mathrm{A} 0\left(\mathrm{x}_{\mathrm{i}}\right)$ is the $\mathrm{A} 0$ value at the $\mathrm{i}^{\text {th }}$ fix-point The process for determining these $\mathrm{A} 0$ values will be explained further down. The derivative of A0 with respect to Modip can then be written as a sum or Epstein transition functions with transition thicknesses $d_{i}$

$$
\begin{aligned}
d A 0 / d x= & m_{1}+\sum_{i=1}^{6}\left(m_{i+1}-m_{i}\right) /(1+\exp [-(x \\
& \left.\left.\left.-x_{i}\right) / d_{i}\right]\right)
\end{aligned}
$$

Integration from $\mathrm{x}_{0}$ to $\mathrm{x}$ then gives us the Bookerfunction that represents the Modip variation of $\mathrm{A} 0$ 

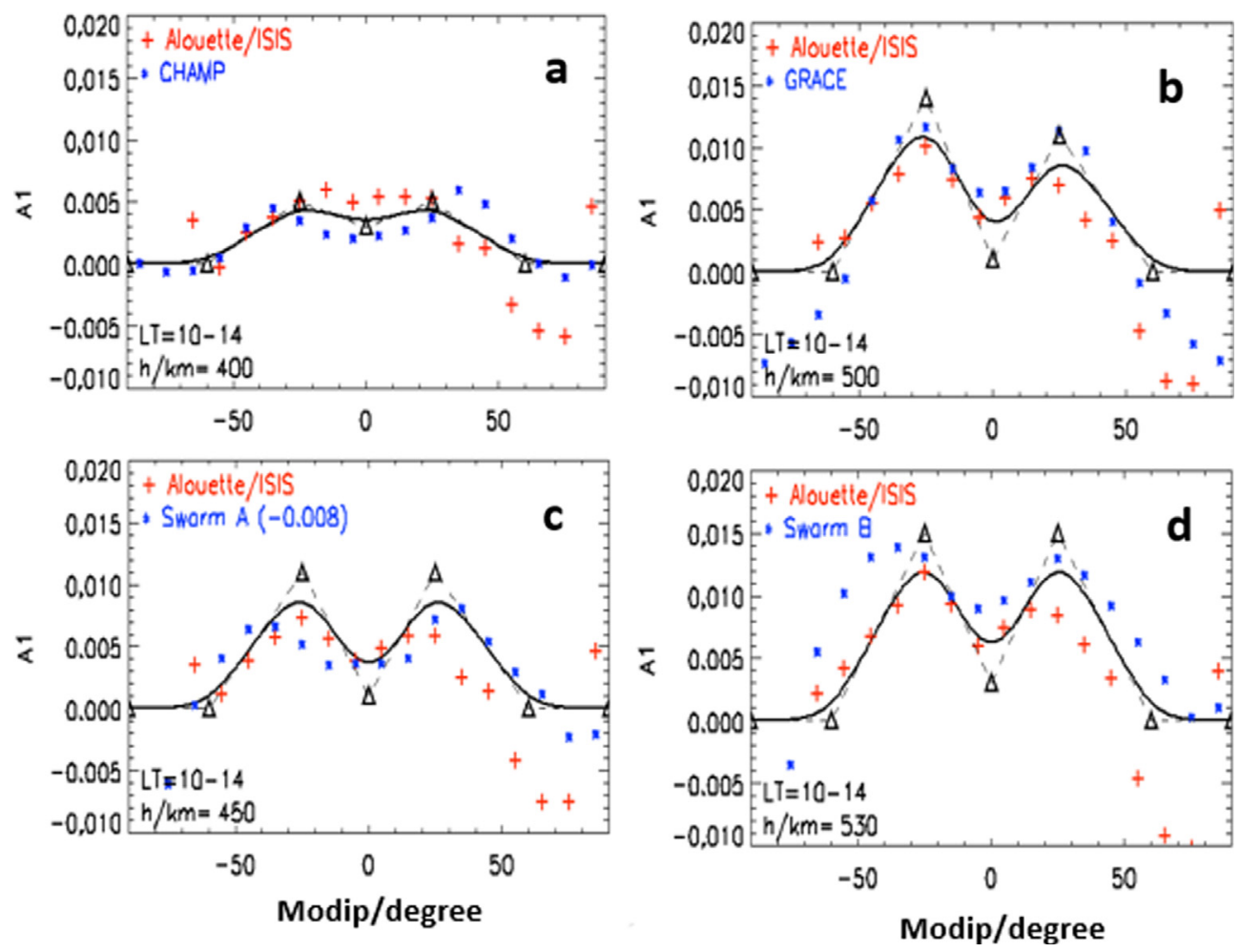

Fig. 5. a,b,c,d. The parameter A1 vs Modip during daytime (LT = 10-14) for the CHAMP data (a, upper left), the GRACE data (b, upper right), the shifted Swarm A data (c, lower left), and the un-shifted Swarm B data (d, lower right) (symbol: blue *). Also shown is A1 obtained from the Alouette/ISIS data (symbol: red + ) for the corresponding altitude range noted in the lower left. The triangles $(\Delta)$ mark the fix-points used for the Booker-function approach and the solid line is the Booker function. NOTE: For a better fit we shifted the Swarm B data by -0.002 (not shown). (For interpretation of the references to color in this figure legend, the reader is referred to the web version of this article.)

$$
\begin{aligned}
A 0= & A 0\left(x_{0}\right)+m_{1} \cdot\left(x-x_{0}\right)+\sum_{i=1}^{6}\left(m_{i+1}-m_{i}\right) \cdot d_{i} \\
& \cdot \ln \left\{\left(1+\exp \left[\left(x-x_{i}\right) / d_{i}\right]\right) /\left(1+\exp \left[\left(x_{0}-x_{i}\right) / d_{i}\right]\right)\right\}
\end{aligned}
$$

We still need to explain how the A0 and A1 values at the fixed Modip values $x_{i}$ were determined. Our effort is primarily concentrated on the Modip range $-60^{\circ}$ to $+60^{\circ}$ because of the large variability at higher Modip latitudes. For this reason, we have set $\mathrm{A} 0\left(-90^{\circ}\right), \mathrm{A} 0\left(-60^{\circ}\right)$, $\mathrm{A} 0\left(+60^{\circ}\right)$ and $\mathrm{A} 0\left(+90^{\circ}\right)$ to zero and thus $\mathrm{m}_{1}$ and $\mathrm{m}_{6}$ become also zero and the same was done for A1. The only parameters varying from plot to plot are therefore the $\mathrm{A} 0$ and A1 values at Modip $=-25^{\circ}, 0^{\circ},+25^{\circ}$. The A0 and A1 values at these fixed Modip values were determined by finding the combination of values that provided the closest fit to the $\mathrm{A} 0$ or $\mathrm{A} 1$ values deduced from the Alouette/ISIS and CHAMP/Grace/Swarm data. The process was started with a first trial set of values and these values were then slowly modified until the optimal fit (lowest model-data differences) was reached. The fix-points (triangles), slopes (dashed lines), and the final Booker-function (solid line) are all included in Figs. 4 and 5 highlighting how well this approach works for the representation of the observed Modip variation of the linear parameters $\mathrm{A} 0$ and A1 during daytime ( $\mathrm{LT}=10: 00-14: 00)$. We find similarly good results with the Booker approach for the nighttime ( $\mathrm{LT}=22: 00-2: 00)$ A0 and A1 values. The next step now is to represent the height variation of the $\mathrm{A} 0$ and A1 values at Modip $=-25^{\circ}, 0^{\circ},+25^{\circ}$ for daytime and nighttime.

\section{Description of the height variation of the parameters A0 and A1}

In Fig. 6 we have plotted the variation of $A 0$ and A1 with height at Modip $=-25^{\circ}, 0^{\circ},+25^{\circ}$ for daytime conditions (LT $=10-14)$. Besides the values from Figs. 4 and 5 for the heights of the CHAMP, GRACE and Swarm orbits we also include values obtained solely based on the Alouette/ISIS data from altitude ranges centered at 700, 800, 900, 1000, 1100, 1200, 1300, $1400 \mathrm{~km}$ (see Fig. 3). We find that $\mathrm{A} 0$ reaches a broad minimum from $700 \mathrm{~km}$ to $1000 \mathrm{~km}$ indicating very large negative corrections in this altitude range and thus significantly lowering the IRI electron density for very low solar activities. The slope A1 reaches a maximum at $700-800 \mathrm{~km}$ indicating a very steep slope of the solar activity dependence at these altitudes. So even though A0 is very low SCOR will be close to zero a medium solar activity and reach positive values at high solar activity so it will make the right corrections to the IRI2001cor formula for the IRI topside electron density. 

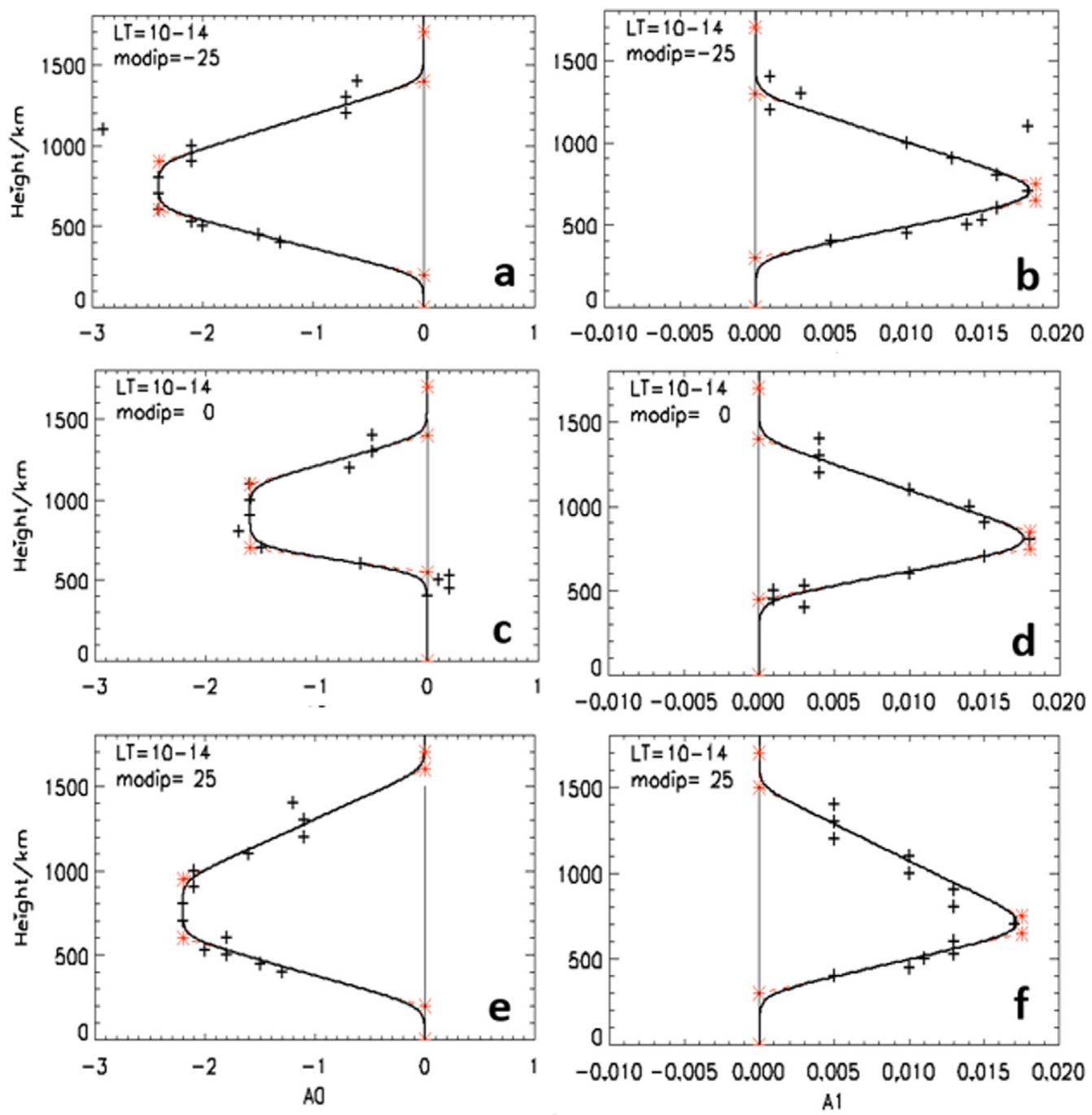

Fig. 6. a,b,c,d,e,f. The parameter A0 vs height during daytime (LT $=10-14)$ for (a) Modip $=-25^{\circ}$, (c) Modip $=0^{\circ}$, and (e) Modip $=25^{\circ}$ and the parameter A1 vs height for (b) Modip $=-25^{\circ}$, (d) Modip $=0^{\circ}$, and (f) Modip $=25^{\circ}$ (symbol: + ). The red asterisks $\left({ }^{*}\right.$ ) mark the fix-points used for the Booker-function approach and the solid line is the Booker function. (For interpretation of the references to color in this figure legend, the reader is referred to the web version of this article.)

To represent these altitudinal variation, we again rely on the Booker approach. As indicated in Fig. 6 we use 6 fixpoints (red asterisks) in altitude $\left(\mathrm{h}_{\mathrm{i}}, \mathrm{i}=1-6\right)$ and we keep the lowest fix- point and the uppermost one at an altitude of $0 \mathrm{~km}$ and $1700 \mathrm{~km}$, respectively. We set the A0 and A1 values at the first two fix-points and the last two fix-points to zero $\left(\mathrm{A} 0 / 1\left(\mathrm{~h}_{\mathrm{i}}\right)=0, \mathrm{i}=1,2,5,6\right)$, because we do not have measurements for these altitude regions. Next we divide the profile in sections of constant gradient and in this way determine the intermediate fix-point altitudes $\mathrm{h}_{2}, \mathrm{~h}_{3}, \mathrm{~h}_{4}$, and $h_{5}$ and the $A 0$ (or A1) values at $h_{3}$ and $h_{4}$. The optimal set of parameters is obtained in the same way as was done for the Modip fix-points by slowly varying these fix-point parameters and calculating the model-data differences. Fig. 6 shows that the Booker approach works very well, closely approximating the satellite values. Only the Modip $=-25^{\circ}$ panels $(6 \mathrm{a}, \mathrm{b})$ include a significant outlying value at $1100 \mathrm{~km}$. This outlier is due to the fact that only a small amount of data and PF10.7 coverage was available for this case. We found that using the fitted values $(\mathrm{A} 0=2.45, \mathrm{~A} 1=0.008)$ gives a satisfying approximation of this limited data case. In Fig. 7 the results are shown for the Booker-fit for the nighttime ( $\mathrm{LT}=22-2)$ case documenting the excellent representation achieved also during nighttime.

The SCOR dependence on Modip, altitude and day/ night conditions is thus determined by a total of $8 \times 3 \times 2=48$ parameters: the four intermediate fixpoint altitudes $\left(\mathrm{h}_{2}, \mathrm{~h}_{3}, \mathrm{~h}_{4}, \mathrm{~h}_{5}\right)$ and the $\mathrm{A} 0$ and $\mathrm{A} 1$ values at the two middle fix-point altitudes (A0/1(h3) and A0/1 (h4)), 8 parameters in total, for the three Modip values $\left(-25^{\circ}, 0^{\circ},+25^{\circ}\right)$ for day and night conditions. For the variation with local time (LT) we assume constant behavior for day and night with continuous transitions at sunrise and sunset. To model this simplified variation pattern, we use the approach that is also used for other IRI parameters and that is based on Epstein step functions (EPST) at the sunrise and sunset local times, LT_SR and LT_SS respec- 

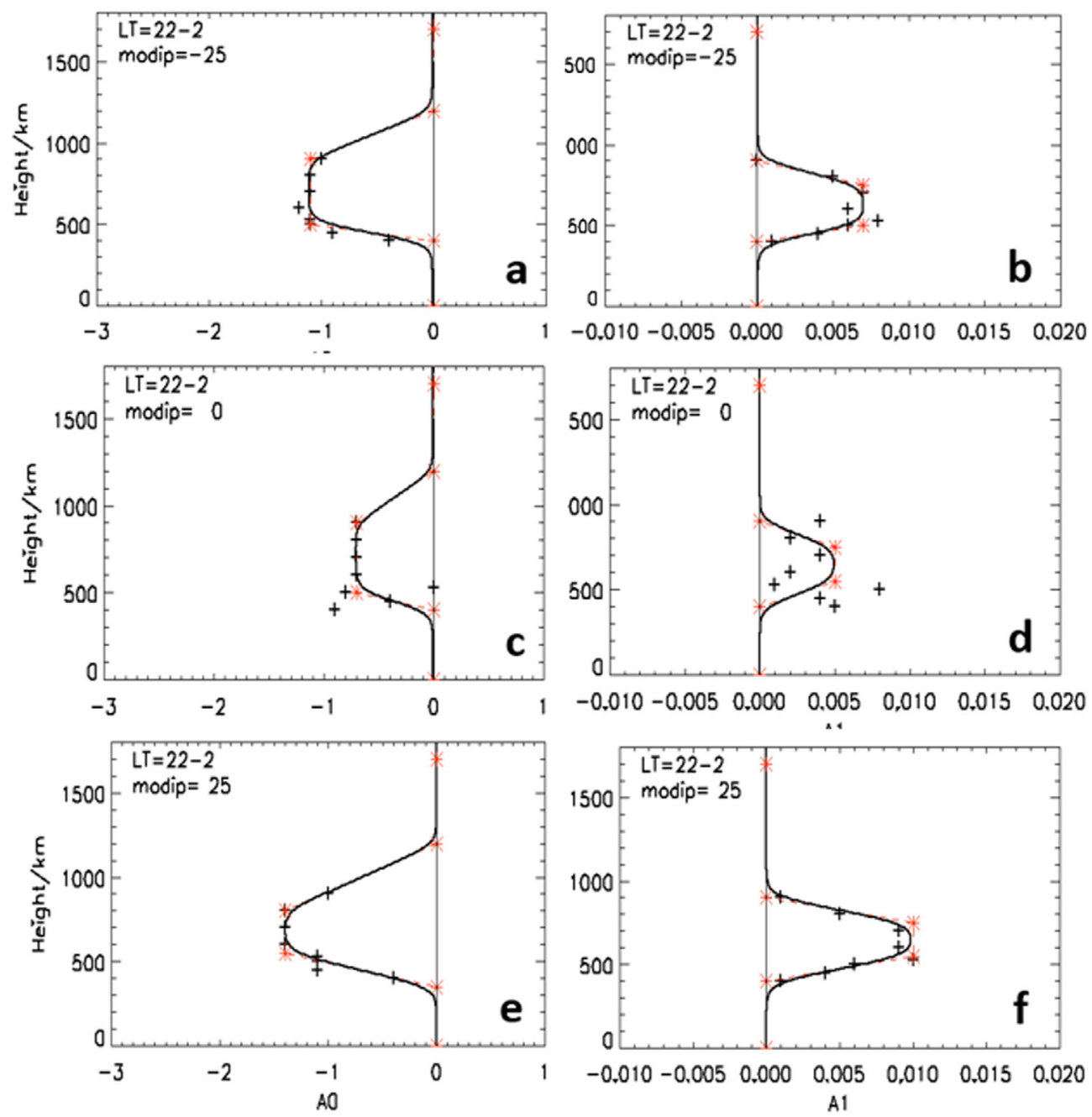

Fig. 7. a,b,c,d,e,f. The parameter A0 vs height during nighttime (LT $=22-2$ ) for (a) Modip $=-25^{\circ}$, (c) Modip $=0^{\circ}$, and (e) Modip $=25^{\circ}$ and the parameter A1 vs height for (b) Modip $=-25^{\circ}$, (d) Modip $=0^{\circ}$, and (f) Modip $=25^{\circ}$ (symbol: + ). The red asterisks $\left({ }^{*}\right)$ mark the fix-points used for the Booker-function approach and the solid line is the Booker function. (For interpretation of the references to color in this figure legend, the reader is referred to the web version of this article.)

tively. For a parameter $\mathrm{P}$ with daytime value PD and nighttime value $\mathrm{PN}$ this is achieved by

$$
\begin{aligned}
P= & P N+(P D-P N) * \operatorname{EPST}\left\{L T, \Delta S R, L T \_S R\right\} \\
& +(P N-P D) * \operatorname{EPST}\left\{L T, \Delta S S, L T \_S S\right\}
\end{aligned}
$$

with the Epstein step-function

$$
\operatorname{EPST}\left\{t, \Delta t, t_{\lrcorner} s t\right\}=1 /\left(1+\exp \left\{-\left(t-t_{s} s t\right) / \Delta t\right\}\right)
$$

and the transition width of $\Delta \mathrm{SR}$ and $\Delta \mathrm{SS}$ for the steps at sunrise and sunset. Here the parameter P is SCOR and we chose a transition width of $1 \mathrm{~h}$ for $\Delta \mathrm{SR}$ and $\Delta \mathrm{SS}$.

\section{Evaluation of the new model}

We have used the satellite data from Tables 1 and 2 to evaluated the new model and assess the improvement over the other IRI topside options. In Fig. 8 Alouette and ISIS topside sounder data are compared to the IRI model pre- dictions with the 'old' IRI-2001cor topside model (left panel) and with the new topside model presented in this paper (we will call this option COR2 from here on) (right panel). We are using the logarithm of the densities to cover the full range of density values encountered during the close to two solar cycles covered by the Alouette and ISIS topside sounder data. The altitude range for this example is $650-750 \mathrm{~km}$, the local time period is 10:00-14:00, and the Modip domain is $20^{\circ}-30^{\circ}$. With the IRI-2001cor option the IRI model overestimates the satellite measurements for low densities (low solar activities) and underestimated the measurements for high densities (high solar activities). The COR2 model with its newly introduced solar activity correction factor SCOR improves the data-model agreement on both ends resulting in a much better fit to the data for low as well as high densities. This is further confirmed with similar plots prepared with the daytime data from the four LEO satellites shown in Fig. 9. The CHAMP and GRACE data cover the low and very low solar activity 

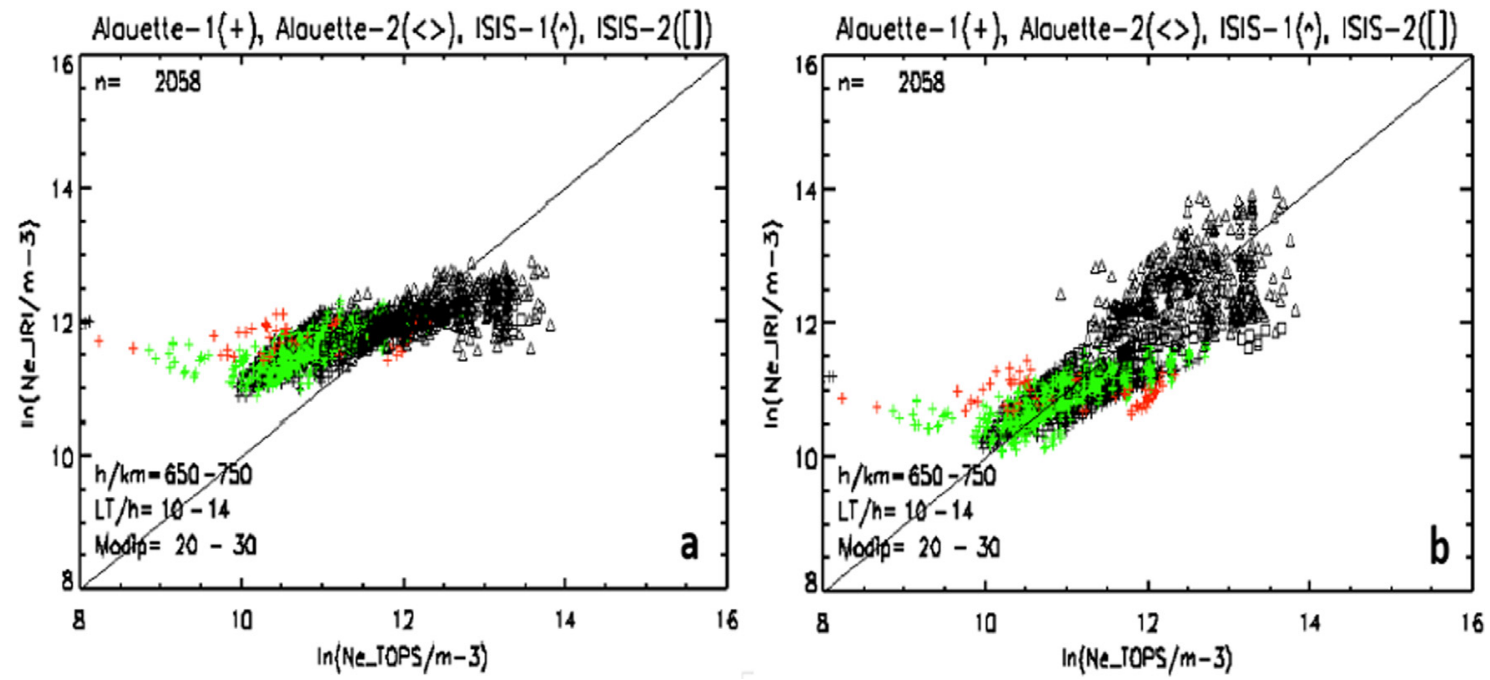

Fig. 8. a,b. Logarithm of electron density observed by the Alouette and ISIS satellites vs IRI predictions for the same conditions computed with the IRI2001 cor option (a, left panel) and with our new COR2 option (b, right panel). Data are taken from the altitude, LT, and Modip range indicated in the lower left of the plot. The total number of data points is listed in the upper left corner. The data sets from Table 1 are marked with different symbols/color: Alouette 1a $(+), 1 \mathrm{~b}(+), 1 \mathrm{c}(+)$, Alouette $2(\diamond)$, ISIS-1 $(\Delta)$, ISIS-2 $(\square)$.
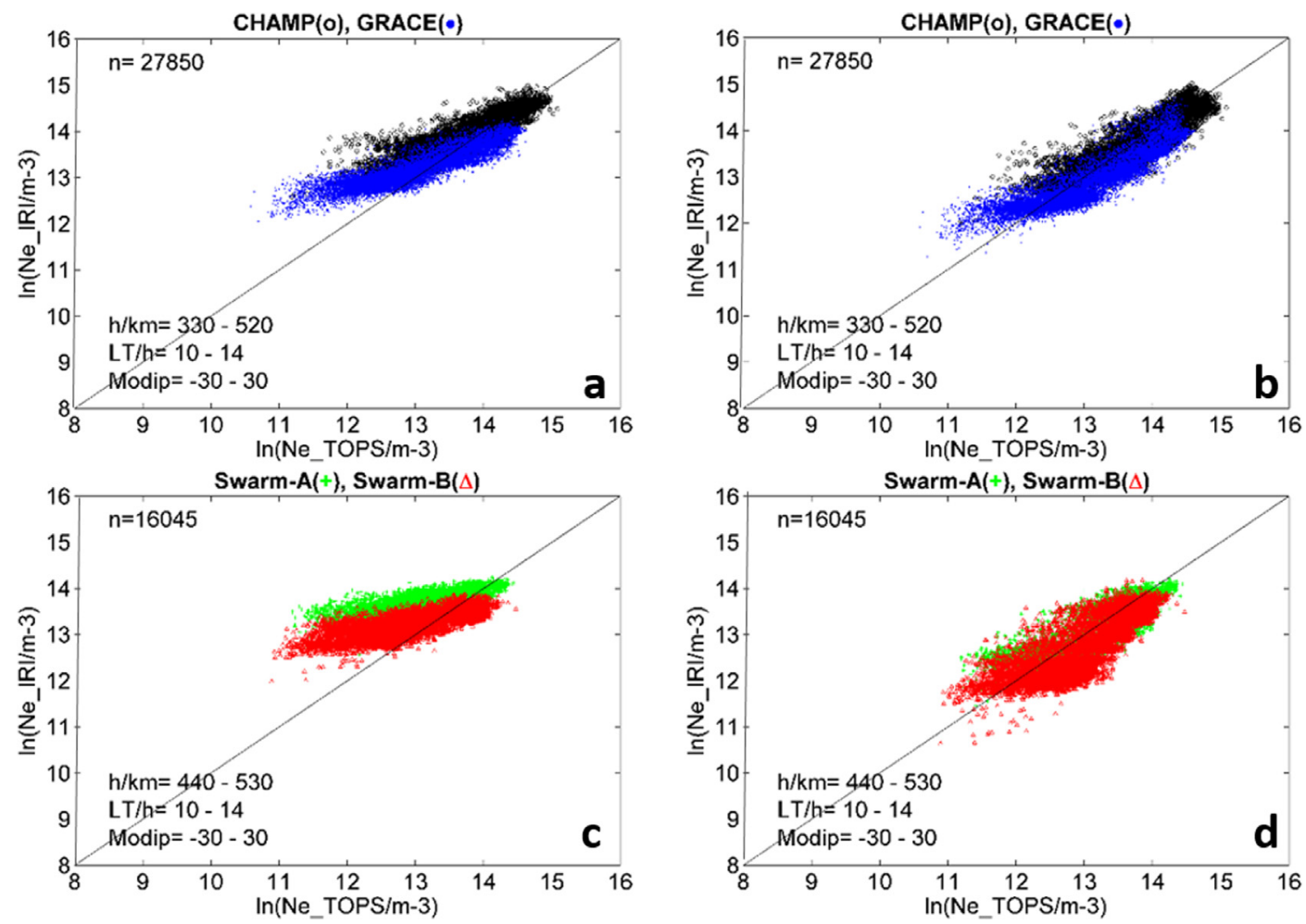

Fig. 9. a,b,c,d. Logarithm of electron density observed by the CHAMP (o), GRACE $(\bullet)$, Swarm A (+) and B ( $\Delta)$ satellites vs IRI predictions for the same conditions computed with the IRI-2001 cor option (a, c, left panel) and with our new COR2 option (b, d, right panel) for daytime conditions. Data are taken from the altitude, LT, and Modip range indicated in the lower left of the plot. The total number of data points is listed in the upper left corner.

regime of the cycle 23-24 minimum, while the Swarm data cover the low solar activity regime of the cycle 24-25. Therefore, our results highlight the improvement reached with the new topside model for very low solar activity conditions.
To look at the achieved performance improvement in greater detail we have plotted the distribution of modeldata relative differences in Fig. 10 for the conditions listed in the top right corner of the plots. These examples for the lowest solar activity values (PF10.7 $=0-90 \mathrm{sfu}$ ) document 

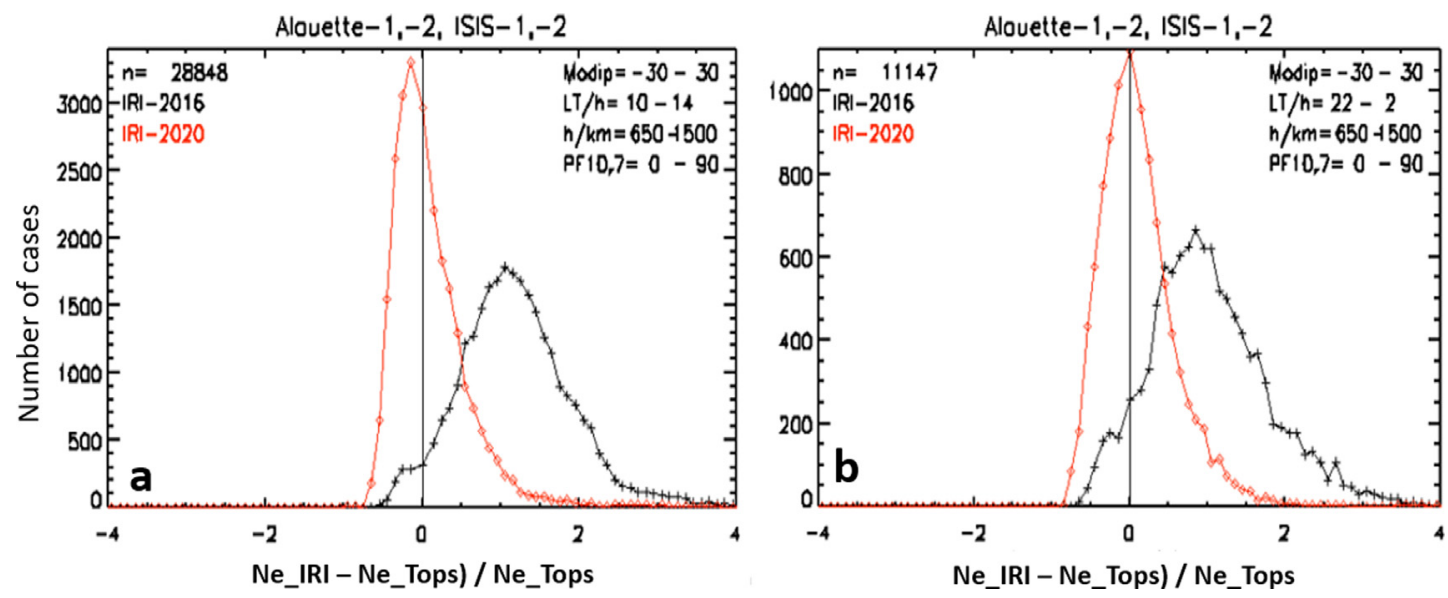

Fig. 10. a,b. Distribution of model-data differences for the IRI-2001cor model (black + ) and the new COR2 model (red $\diamond$ ) with the Alouette and ISIS data from Table 1 for the conditions given in the upper right corner. The number in the upper left corner gives the total number of data points found for these conditions. (For interpretation of the references to color in this figure legend, the reader is referred to the web version of this article.)

the significant improvement achieved with the new model. The distribution for the old IRI2001cor model (black line in Fig. 10) peaks close to 1 corresponding to a factor of 2 overestimation of the data, while the distribution with the new model (red curve in Fig. 10) is perfectly centered at zero. Taken across the whole Alouette/ISIS data set the mean percentage data-model difference is $-67 \%$ for IRI2001cor, $-36 \%$ for COR2, and $-42 \%$ for NeQuick. All three models overestimate the Alouette/ISIS topside sounder data. With the addition of the new solar-activity correction factor the overestimation of the IRI2001cor model was almost cut in half, achieving almost a factor of two improvement over the older model and getting a $6 \%$ better result than the NeQuick topside option which is the current default for the topside in IRI.

Fig. 11 shows further the relative annual deviations between the 'old' IRI-2001cor topside model (dashed lines) and the new topside model (solid lines), with respect to the in situ electron density measurements from the four LEO satellites. We see clearly that after applying the solar activity correction factor, the differences between IRI model and satellite measurements have reduced from over $100 \%$ to

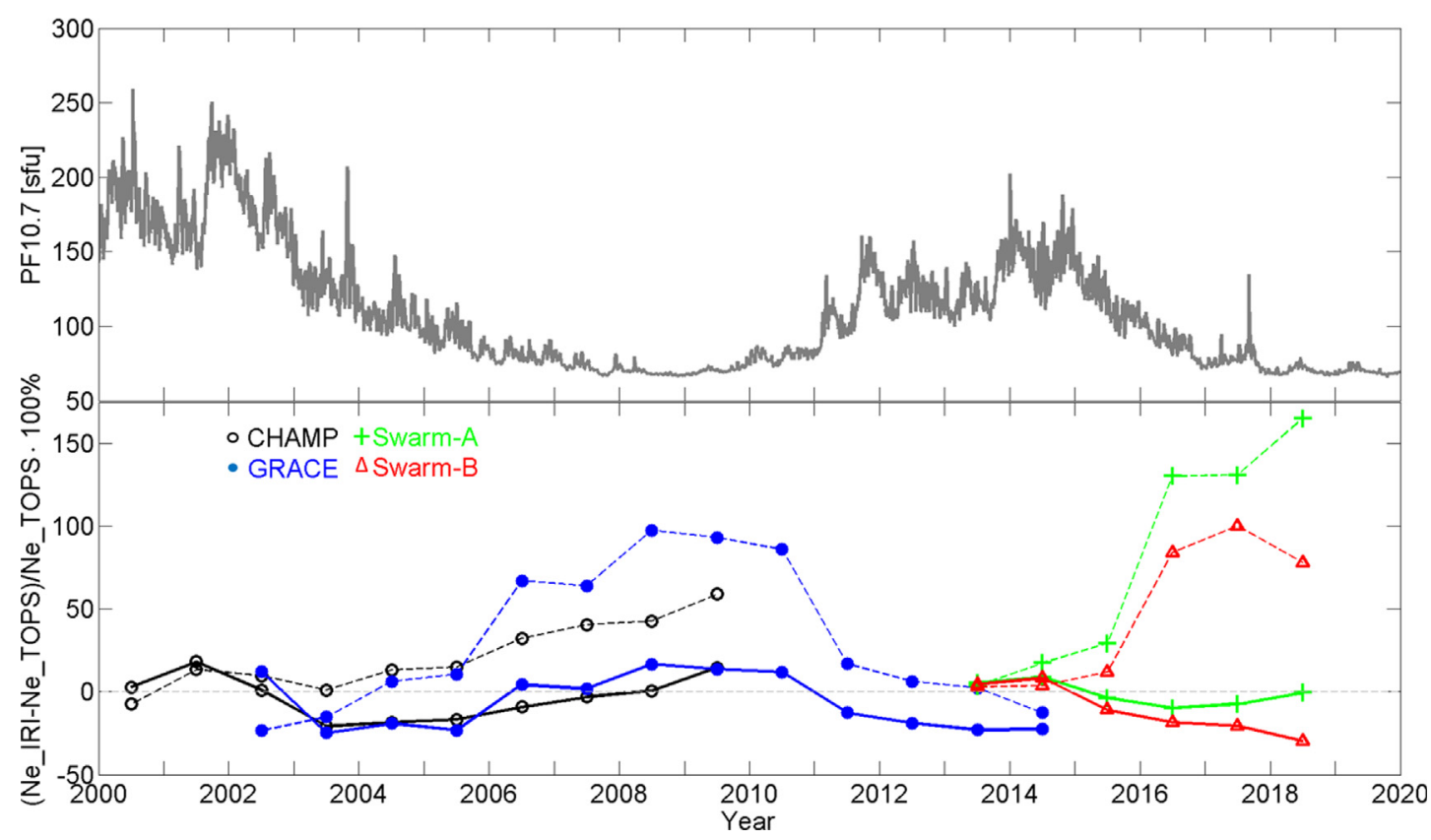

Fig. 11. The annual difference between the 'old' IRI-2001cor topside model (dashed lines) and the new topside model (solid lines), with respect to the in situ electron density measurements from the four LEO satellites. The solar activity index, PF10.7, is shown as the grey line in the top panel. 
less than $20 \%$ during low solar activity years in both 2008 2009 and 2017-2018. Please note that here we considered only the data during magnetic quiet periods $(\mathrm{Kp}<3)$, $10-14$ LT, and Modip within $\pm 30^{\circ}$.

\section{Summary}

A number of studies had found that the IRI model overestimates topside electron densities during the recent unusually low solar cycle minimum in 2008-2009 (Lühr and Xiong, 2010; Klenzing et al., 2011, 2013; Bilitza et al., 2012). Earlier studies had also noted underestimation of topside electron densities during periods of high solar activity. In both cases these effects were most prominent in low latitudes. Using ionosonde data Bilitza et al. (2012) had found that the main cause of the overestimation at low solar activities was the insufficient accounting for solar activity changes in the IRI topside profile formula. In this study we have developed a solar activity dependent correction term for the current IRI2001cor option for the topside electron density. The correction term assumes a linear variation with the solar activity index PF10.7, with the linear coefficients varying with modified dip latitude (Modip), with altitude, and with time of day. In our model these variations are described with Epstein functions using the Booker approach which is based on dividing the parameter space into region of constant slope. In total the correction term is defined by 48 coefficients.

Our evaluation of the new topside model shows a significant improvement over the old IRI2001cor topside model and the new COR2 model also outperforms the NeQuick topside model that is currently the default for the representation of the topside electron density in IRI. The percentage deviation from the Alouette/ISIS data (consisting of 176,622 profiles) is $-67 \%$ for IRI2001cor, $-36 \%$ for COR 2 , and $-42 \%$ for NeQuick. CHAMP, GRACE, and Swarm data confirm these results finding an improved correlation with IRI when using the COR2 topside model. However, we find that, while the CHAMP and GRACE data agree well with the Alouette/ISIS data in the corresponding height range, this is not the case for the Swarm data. The A0 and A1 values deduced from Swarm A and $\mathrm{B}$ data show the best fit with the corresponding Alouette/ ISIS values when shifted by a small amount. For A0 this shift is +1.4 for Swarm A and +0.5 for Swarm B and for A1 the shift is -0.008 for Swarm A and -0.002 for Swarm $B$. These shifts translate into multiplicative calibration factors for electron density of $1.82 / 1.35$ (Swarm A/B) at PF10.7 = $100 \mathrm{sfu}, 1.49 / 1.285$ at PF10.7 = $125 \mathrm{sfu}$ (which is about the middle of the PF10.7 range covered by the Swarm data in Fig. 2), and 1.22/1.22 for PF10.7 = 150 sfu (which is about the upper limit of the PF10.7 range covered by the Swarm data in Fig. 2). These corrections are in the same directions but a little bit larger than the adjustment ratios Lomidze et al. (2018) had found in their validation study with incoherent scatter radar and satellite radio occultation measurements: 1.1067 for Swarm A and 1.0882 for Swarm B.

\section{Declaration of Competing Interest}

The authors declare that they have no known competing financial interests or personal relationships that could have appeared to influence the work reported in this paper.

\section{Acknowledgement}

We acknowledge the use of the IRI model available from http://irimodel.org and of the Alouette 1,2 and ISIS 1,2 topside sounder data available from NASA's Space Physics Data Facility (SPDF) at https://spdf.gsfc.nasa.gov. The CHAMP and GRACE data were obtained from the Information System and Data Center (ISDC) of GFZ German Research Centre for Geosciences (https://isdc.gfzpotsdam.de/homepage/). The Swarm data are available at the ESA's website ftp://swarm-diss.eo.esa.int/Levellb/Lat est_baselines/EFIx_LP/. Chao Xiong was partly supported by the TIRO project under subcontract No. SW-CO-DTUGS-126 within ESA's DISC under contract No. 4000109587/13/I-NB.

\section{References}

Abdu, M.A., Brum, C.G.M., Batista, I.S., Sobral, J.H.A., de Paula, E.R., Souza, J.R., 2008. Solar flux effects on equatorial ionization anomaly and total electron content over Brazil: Observational results versus IRI representations. Adv. Space Res. 42, 617-625. https://doi.org/10.1016/ j.asr.2007.09.043.

Altadill, D., Magdaleno, S., Torta, J.M., Blanch, E., 2013. Global empirical models of the density peak height and of the equivalent scale height for quiet conditions. Adv. Space Res. 52, 1756-1769. https:// doi.org/10.1016/j.asr.2012.11.018.

Benson, R.F., Bilitza, D., 2009. New satellite mission with old data: Rescuing a unique data set. Radio Sci. 44, RS0A04. https://doi.org/ 10.1029/2008RS004036.

Bent, R.B., Llewellyn, S.K., Schmid, P.E., 1972. Description and evaluation of the Bent ionospheric model, vols. 1, 2, and 3, Space and Missile Systems Organization Report SAMSO TR-72-239, National Technical Information Service, AD-753-081, -082, -083, Springfield, VA.

Bilitza, D., 2004. A correction for the IRI topside electron density model based on Alouette/ISIS topside sounder data. Adv. Space Res. 33 (\#6), 838-843. https://doi.org/10.1016/j.asr.2003.07.009.

Bilitza, D., 2009. Evaluation of the IRI-2007 model options for the topside electron density. Adv. Space Res. 44, 701-706. https://doi.org/10.1016/ j.asr.2009.04.036.

Bilitza, D., 2018. IRI the International Standard for the Ionosphere. Adv. Radio Sci. 16, 1-11. https://doi.org/10.5194/ars-16-1-2018.

Bilitza, D., Reinisch, B., Benson, R., Grebowsky, J., Papitashvili, N., Huang, X., Schar, W., Hills, K., 2003. Online data base of satellite sounder and insitu measurements covering two solar cycles. Adv. Space Res. 31 (\#3), 769-774. https://doi.org/10.1016/S0273-1177(03) 00051-6.

Bilitza, D., Huang, X., Reinisch, B., Benson, R., Hills, H.K., Schar, W.B., 2004. Topside ionogram scaler with true height algorithm (TOPIST): Automated processing of ISIS topside ionograms RS1S27. Radio Sci. 39 (1). https://doi.org/10.1029/2002RS002840.

Bilitza, D., Brown, S.A., Wang, M.Y., Souza, J.R., Roddy, P.A., 2012. Measurements and IRI model predictions during the recent solar 
minimum. J. Atmos. Solar-Terr. Phys. 86, 99-106. https://doi.org/ 10.1016/j.jastp.2012.06.010.

Bilitza, D., Altadill, D., Truhlik, V., Shubin, V., Galkin, I., Reinisch, B., Huang, X., 2017. International Reference Ionosphere 2016: From ionospheric climate to real-time weather predictions. Space Weather 15, 418-429. https://doi.org/10.1002/2016SW001593.

Heelis, R.A., Coley, W.R., Burrell, A.G., Hairston, M.R., Earle, G.D., Perdue, M.D., Power, R.A., Harmon, L.L., Holt, B.J., Lippincott, C. R., 2009. Behavior of the $\mathrm{O}+/ \mathrm{H}+$ transition height during the extreme solar minimum of 2008. Geophys. Res. Lett. 36, L00C03. https://doi. org/10.1029/2009GL038652.

Klenzing, J., Simões, F., Ivanov, S., Heelis, R.A., Bilitza, D., Pfaff, R., Rowland, D., 2011. Topside equatorial ionospheric density and composition during and after extreme solar minimum. J. Geophys. Res. 116, A12330. https://doi.org/10.1029/2011JA017213.

Klenzing, J., Simões, F., Ivanov, S., Bilitza, D., Heelis, R.A., Rowland, D., 2013. 2013, Performance of the IRI-2007 model for equatorial topside ion density in the African sector for low and extremely low solar activity. Adv. Space Res. 52 (10), 1780-1790. https://doi.org/ 10.1016/j.asr.2012.09.030.

Liu, L., Wan, W., Ning, B., Pirog, O.M., Kurkin, V.I., 2006. Solar activity variations of the ionospheric peak electron density. J. Geophys. Res. 111, A08304. https://doi.org/10.1029/2006JA011598.

Lomidze, L., Knudsen, D.J., Burchill, J., Kouznetsov, A., Buchert, S.C., 2018. Calibration and validation of Swarm plasma densities and electron temperatures using ground-based radars and satellite radio occultation measurements. Radio Sci. 53, 15-36. https://doi.org/ 10.1002/2017RS006415.

Lühr, H., Xiong, C., 2010. IRI-2007 model overestimates electron density during the 23/24 solar minimum. Geophys. Res. Lett. 37, L23101. https://doi.org/10.1029/2010GL045430.

Nava, B., Cor"sson, P., Radicella, S.M., 2008. A new version of the NeQuick ionosphere electron density model. J. Atmos. Sol.-Terr. Phys., 70, 1856-1862 doi: 10.1016/j.jastp.2008.01.015.

Mengist, C.K., Yadav, S., Kotulak, K., Bahar, A., Zhang, S.-R., Seo, K. H., 2020. Validation of International Reference Ionosphere model (IRI-2016) for F-region peak electron density height (hmF2): Comparison with Incoherent Scatter Radar (ISR) and ionosonde measurements at Millstone Hill. Adv. Space Res. 65, 2773-2781. https://doi. org/10.1016/j.asr.2020.03.017.

Moses, M., Bilitza, D., Sharma, S.K., Panda, S.K., Ochonugor, B.J., 2021. Assessment of IRI-2016 hmF2 Model Predictions with COSMIC Observations over the African Region, Adv. Space Res. (2021) (in press).

Ogwala, A., Somoye, E.O., Ogunmodimu, O., Adeniji-Adele, R.A., Onori, E.O., Oyedokun, O., 2019. Diurnal, seasonal and solar cycle variation in total electron content and comparison with IRI-2016 model at Birnin Kebbi. Ann. Geophys. 37, 775-789. https://doi.org/10.5194/ angeo-37-775-2019.

Radicella, S.M., Leitinger, R., 2001. The evolution of the DGR approach to model electron density profiles. Adv. Space Res. 27 (1), 35-40. https://doi.org/10.1016/S0273-1177(00)00138-1.

Richards, P.G., Fennelly, J.A., Torr, D.G., 1994. EUVAC: a solar EUV flux model for aeronomic calculations. J. Geophys. Res. 99 (A5), 89818992. https://doi.org/10.1029/94JA00518.

Shim, J.S., Kuznetsova, M., Rastätter, L., Hesse, M., Bilitza, D., Codrescu, M., Emery, B., Foster, B., Fuller-Rowell, T., Huba, J., Mannucci, A.J., Ridley, A., Scherliess, L., Schunk, R.W., Stephens, P., Thompson, D.C., Zhu, L., Anderson, D., Chau, J.L., Sojka, J.J., Rideout, B., 2011. CEDAR Electrodynamics Thermosphere Iono- sphere 1 (ETI) Challenge for Systematic Assessment of Ionosphere/ Thermosphere Models 1: NmF2, hmF2, and Vertical Drift Using Ground Based Observations. Space Weather 9, S12003. https://doi. org/10.1029/2011SW000727.

Shim, J.S., Kuznetsova, M., Rastätter, L., Hesse, M., Bilitza, D., Butala, M., Codrescu, M., Emery, B.A., Foster, B., Fuller-Rowell, T.J., Huba, J., Mannucci, A.J., Pi, X., Ridley, A., Scherliess, L., Schunk, R.W., Sojka, J.J., Stephens, P., Thompson, D.C., Weimer, D., Zhu, L., Sutton, E., 2012. CEDAR Electrodynamics Thermosphere Ionosphere (ETI) Challenge for systematic assessment of ionosphere/thermosphere models: Electron density, neutral density, $\mathrm{NmF} 2$, and hmF2 using space based observations. Space Weather 10, S10004. https://doi. org/10.1029/2012SW000851.

Rawer, K., Bilitza, D., Ramakrishnan, S., Sheikh, N, 1978, Intentions and build-up of the International Reference Ionosphere, in: Operational Modelling of the Aerospace Propagation Environment, AGARD Conference Proceedings No. 238. Paris, pp. 6-1-6-9.

Shim, J.S., Rastätter, L., Kuznetsova, M., Bilitza, D., Codrescu, M., Coster, A.J., Emery, B.A., Fedrizzi, M., Förster, M., Fuller-Rowell, T. J., Gardner, L.C., Goncharenko, L., Huba, J., McDonald, S.E., Mannucci, A.J., Namgaladze, A.A., Pi, X., Prokhorov, B.E., Ridley, A.J., Scherliess, L., Schunk, R.W., Sojka, J.J., Zhu, L., 2017, CEDARGEM challenge for systematic assessment of Ionosphere/thermosphere models in predicting TEC during the 2006 December storm event, Space Weather, 15, 1238-1256, doi: 10.1002/2017SW001649.

Shim, J.S., Tsagouri, I., Goncharenko, L., Rastaetter, L., Kuznetsova, M., Bilitza, D., Codrescu, M., Coster, A.J., Solomon, S.C., Fedrizzi, M., Förster, M., Fuller-Rowell, T.J., Gardner, L.C., Huba, J., Namgaladze, A.A., Prokhorov, B.E., Ridley, A.J., Scherliess, L., Schunk, R. W., Sojka, J.J., Zhu, L., 2018. Validation of ionospheric specifications during geomagnetic storms: TEC and foF2 during the 2013 March storm event. Space Weather, 16, 1686-1701, doi: 10.1029/ 2018 SW002034.

Shubin, V.N., 2015. Global median model of the F2-layer peak height based on ionospheric radio-occultation and ground-based digisonde observations. Adv. Space Res. 56, 916-928. https://doi.org/10.1016/j. asr.2015.05.029.

Truhlik, V., Bilitza, D., Triskova, L., 2015. Towards better description of solar activity variations in IRI ion composition model. Adv. Space Res. 55 (8), 2099-2105. https://doi.org/10.1016/j.asr.2014.07.033.

Verhulst, T., Stankov, S.M., 2013. The topside sounder database - Data screening and systematic biases. Adv. Space Res. 51 (11), 2010-2017. https://doi.org/10.1016/j.asr.2012.12.023.

Wan, Qingtao, Guanyi, Ma, Jinghua, Li, Xiaolan, Wang, Weijun, Lu, Takashi, Maruyama, Jiangtao, Fan, Jie, Zhang, 2020, Performance evaluation of IRI-2016 with GPS-derived TEC at the meridian of $110^{\circ}$ E in China of 2014, J. Atmos. Sol.-Terr. Phys., 201, 105206, doi: 10.1016/j.jastp.2020.105206.

Xiong, C., Park, J., Lühr, H., Stolle, C., Ma, S.Y., 2010. Comparing plasma bubble occurrence rates at CHAMP and GRACE altitudes during high and low solar activity. Annales Geophysicae 28, 16471658. https://doi.org/10.5194/angeo-28-1647-2010.

Xiong, C., Lühr, H., Ma, S., Schlegel, K., 2015. Validation of GRACE electron densities by incoherent scatter radar data and estimation of plasma scale height in the topside ionosphere. Adv. Space Res. 55 (8), 2048-2057. https://doi.org/10.1016/j.asr.2014.07.022.

Xiong, C., Zhou, Y.-L., Lühr, H., Ma, S.-Y., 2016. Diurnal evolution of the $\mathrm{F}$ region electron density local time gradient at low and middle latitudes resolved by the Swarm constellation. J. Geophys. Res. 121, 9075-9089. https://doi.org/10.1002/2016JA023034. 